\title{
Peri Implant Aesthetics - An Integrated Review
}

\author{
Priyanka Anil Sonavane1, Jasuma Rai², Mudra Sanjay Andharia³ \\ 1, 2,3 Department of Periodontology, K M Shah Dental College and Hospital, \\ Sumandeep Vidyapeeth (Deemed to be University), Vadodara, Gujarat, India.
}

\section{ABSTRACT}

\section{BACKGROUND}

Aesthetic dentistry is making its own new position in current scenario. The aesthetic desire of patient has become need of an hour and it is essential for dental practitioner to understand the aesthetics of implants. For planning of implants in anterior region, overall general health of patient should be considered including systemic health, good oral hygiene practice and good compliance of patients. The peri-implant aesthetics is determined by two components - soft tissue and hard tissue, which includes bone and gingiva. Modifications refining the tissues around implant can enhance the aesthetics. Treatment protocol should include pre-planning of all functional and aesthetic considerations which should be discussed to patients as well prior to preceding treatment of implant. Judicious understanding of these factors can not only provide physical integrity of tissue but also prevent future aesthetics and implant failure. Implants in anterior region become challenging for clinicians to emulate what nature has provided. The harmonious relationship between functional stability and peri-implant soft tissue becomes an essential requisite for successful endosseous implant so as to attain proper facial aesthetics. Visualization of aesthetics related to implants is a complex phenomenon which requires utilization of multidisciplinary approach including prosthetic and periodontal consideration as the implant position as well implant abutment junction if placed at improper position can cause bone resorption. Compiling this, comprehensive knowledge regarding soft and hard tissue can help dentists to integrate a balance between the smile and face of an individual. This review article is a detailed endeavour to explore peri-implant aesthetics.

\section{KEY WORDS}

Crestal Bone, Dental Aesthetics, Gingiva, Peri-Implant Aesthetics
Corresponding Author:

Dr. Jasuma Rai,

Department of Periodontology,

Room No. 7,

K M Shah Dental College and Hospital, Sumandeep Vidyapeeth,

Vadodara -391760, Gujarat, India.

E-mail: drjasumaj@gmail.com

DOI: $10.14260 / j e m d s / 2021 / 729$

How to Cite This Article:

Sonavane PA, Rai J, Andharia MS. Peri implant aesthetics - an integrated review. J Evolution Med Dent Sci 2021;10(41):35983603, DOI: 10.14260/jemds/2021/729

Submission 06-07-2021,

Peer Review 21-09-2021,

Acceptance 27-09-2021,

Published 11-10-2021.

Copyright (c) 2021 Priyanka Anil Sonavane et al. This is an open access article distributed under Creative Commons Attribution License [Attribution 4.0 International (CC BY 4.0)] 


\section{BACKGROUND}

The concept of implant is not just limited to fulfilment of the functional needs but also to provide appealing natural look. Problems concerned to anterior teeth aesthetics in periimplant area was first given by Palacci P in $1995 .{ }^{1}$

Single tooth replacement with a dental implant in anterior region has achieved popularity in recent years because it prevents alteration of adjacent tooth structure and halts the resorption of edentulous spaces to provide support for the prosthesis.

However, current aesthetic demands of clinicians as well as the expectations of patients continue to grow, to fulfil these requirements, dentists have to take into account the fine periimplant tissue details as well as prosthesis in order to produce natural look.

Aesthetic output of implant or peri-implant tissue is not governed by any one factor but is a compound association of multiple factors.

\section{Search Strategy}

The research articles were searched on electronic databases PubMed, Google scholar, Trip database, Cochrane database and hand searches in six periodontal and two implant journals during the year July 1995 to June 2021. The time period for this review has been selected as the first mention of peri implant aesthetics which was done in 1995 and further incorporation of evidence is done till 2021. This article is a detailed approach to explore aesthetics around dental implants.

The peri-implant area contains both soft tissue (gingiva) and hard tissue (crestal bone) encompassing it. For accomplishing such aesthetic and functionally compatible implants, one should know all the factors to be considered that will affect implant as well as peri implant soft tissue aesthetics. The architecture of soft and hard tissues plays a crucial role in achieving implant aesthetics.

\section{FACTORS RESPONSIBLE FOR IDEAL PERI-IMPLANT AESTHETICS}

\section{Soft Tissue Factors}

1. Supracrestal attachment, 2. Crestal bone height, 3. Tooth form and shape, 4. Interproximal distance, 5. Gingival phenotype, 6. Interdental papillary aesthetics, 7. Position of tooth, amount of keratinized tissue, type of gingival tissue scallop, and 8. Smile line

\section{Hard Tissue Factors}

1. The platform switch concept, 2. Collar geometry and micro gap 3. Size of the implant and 4. Abutment disconnection and microlesions.

\section{Soft Tissue Consideration}

Peri implant soft tissue lies under the contact point between two adjacent implants or a natural tooth and an implant. The soft tissue aesthetics directly or indirectly depend on factors such as height of crestal bone, amount of interproximal distance, shape and form of tooth. Some factors like gingival thickness, gingival phenotype and lip line also determine the implant aesthetics.

\section{Soft Tissue Factors}

Supracrestal Attachment

The implant, epithelium and the connective tissue are in contact with each other. The overall contact length between the three portions is defined as the biological width. Based on the Classification of Periodontal and Peri-Implant Diseases and Conditions given World Workshop in 2017, ${ }^{2}$ the term biologic width is substituted by supracrestal tissue attachment. It is composed of junctional epithelium (JE) and supracrestal connective tissue. In natural tooth, supracrestal tissue attachment usually consists of $0.97 \mathrm{~mm}$ junctional epithelium and $1.07 \mathrm{~mm}$ connective tissue attachment (Figure 1). Thus, the biologic width is calculated to be $2.04 \mathrm{~mm}$. Periimplant tissues show some variations with respect to periodontal attachment apparatus. These variations can be appreciated along the periodontal ligament around implants, course of connective tissue fibers and vascular distribution. ${ }^{3}$

The resemblance has been demonstrated between dimension of the peri-implant mucosa and the gingiva at tooth which includes a epithelial portion of $2-\mathrm{mm}$ and a connective tissue portion of about $1-1.5 \mathrm{~mm}^{4,5}$ (Figure 2). Whenever the thickness of the peri-implant mucosa is condensed, the compensatory bone resorption occurs to refurbish the dimension of mucosa which is essential to shield the underlying tissues. ${ }^{6}$ Long lasting conservation of the healthy peri-implant tissues is prime concern for ensuring functional proficiency and demanding aesthetics. Study done by Levin EI et al. (1978) has shown that the bone resorption around the implant neck occurs only after implant neck is exposed to the oral cavity, leading to accumulation of microbes in the area of implant abutment junction (IAJ). This event ultimately causes bone remodelling so as to achieve biologic width. $7,8,9$ To establish a functional biologic soft tissue seal, a minimal dimension of biologic width is essential. ${ }^{10}$

\section{Crestal Bone Height}

The osseous architecture of underlying bone is the prime component for the organization and support of the gingival tissue $e^{5,10}$ The classic study by Tarnow (1992) demonstrated that the crestal bone height has direct effect on and the dental papilla. Nearly complete papilla fill is observed when the distance from contact bone to contact point is $\leq 5 \mathrm{~mm}$. The single dental implant papilla regeneration is less complicated when compared to two adjacent implants. ${ }^{11}$ It was found that platform switching implants show lower crestal bone loss compared to the non-platform switched implant. $3 \mathrm{~mm}$ is considered as ideal distance from the base of the contact point to the bone crest between adjacent implants, while within tooth and the implant, it is $<5 \mathrm{~mm} .{ }^{9}$ The size of implant varies with the amount of edentulous space available among two natural teeth or tooth-implant. The minimal space required for different implants is explained in figures $3 \& 4.12,13$ ideally in anterior region, implant should have a minimum gap of $6 \mathrm{~mm}$ mesiodistally which provides a distance of around $1.5 \mathrm{~mm}$ from adjacent teeth. ${ }^{14}$ For implant placement in anterior region, minimum $6 \mathrm{~mm}$ of bone dimension is required 
buccolingually to provide $1.5 \mathrm{~mm}$ bone on facial site and at least $0.5 \mathrm{~mm}$ on palatal site.
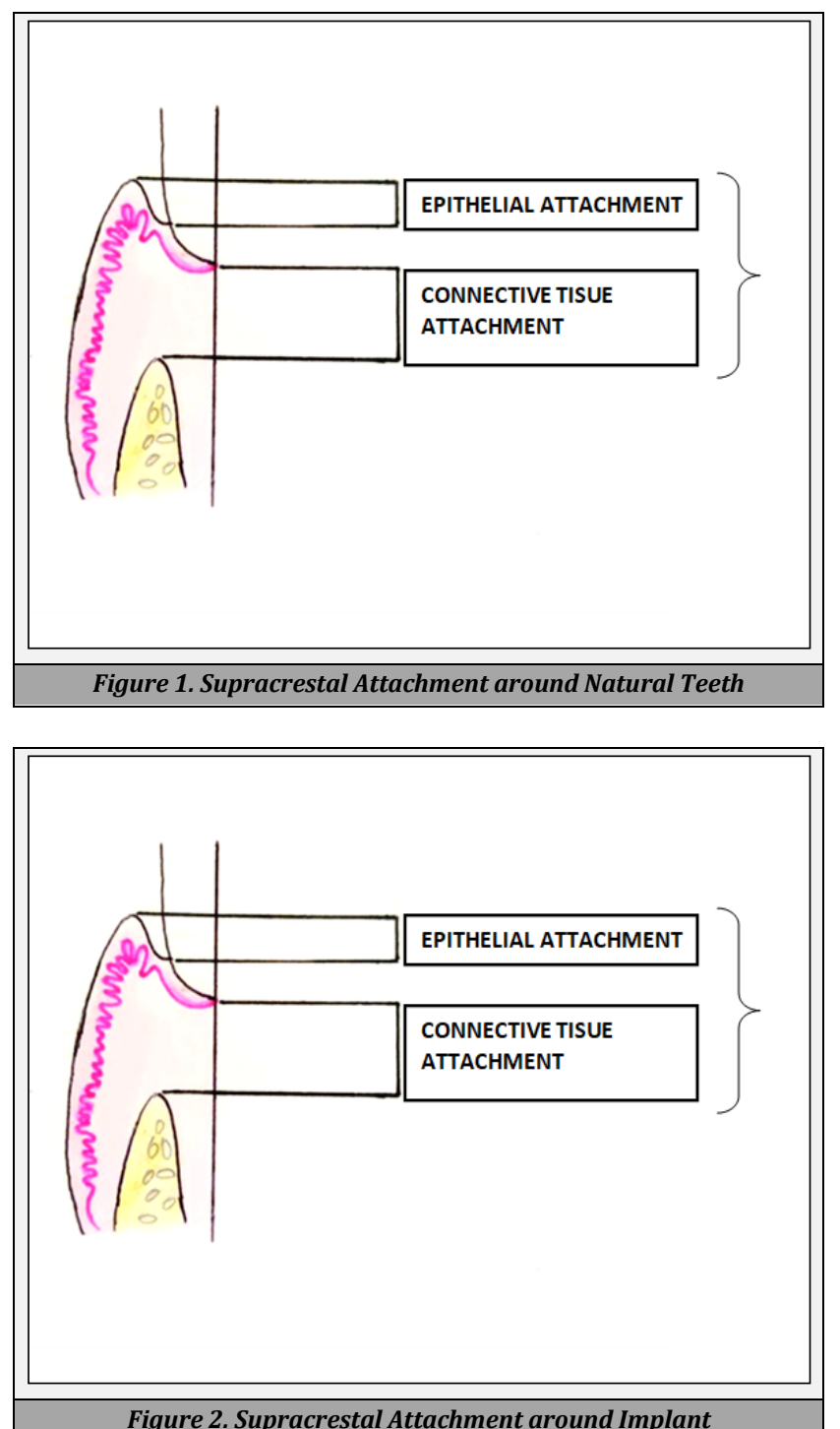

Form and Shape of Tooth

The morphology of teeth plays crucial role in natural dentition, as the gingiva follows the morphology of tooth. Square, triangular and ovoid are the different types of tooth shape and short, wide, long and narrow are the distinct classes of tooth form. The study done by Olsson and Lindhe (1991) observed that the subjects exhibiting long narrow tooth form demonstrated a thin free gingival phenotype, pronounced scalloped contour of the gingival margin and shallow probing depth. ${ }^{15}$ Likewise, the tooth form and shape influence the periimplant soft tissue architecture. Tooth shape is considered in one of the five essential diagnostic factors for the peri-implant esthetics. ${ }^{16}$ Square shaped teeth have more positive aesthetic outcomes due to its long interproximal contact and less of the inter papillary tissue, while triangular shape of teeth need more tissue height to fill in as the proximal contact is located more incisal and hence shows potential risk of the black hole disease.

\section{Interproximal Distance}

Tarnow (2000) revealed that at least $3 \mathrm{~mm}$ of the interimplant distance between two implants or implant \& tooth is essential to have a healthy crestal bone in between. The interproximal distance affects the appearance of the hard and soft tissues. When the distance between two roots is less than $0.5 \mathrm{~mm}$, it leads to development of thin lamina dura and in cases where it is around $0.3 \mathrm{~mm}$, the crestal bone will be rarely present connecting roots directly to periodontal ligament. Ideally, inter-root distance should be $5 \mathrm{~mm}$ vertically and 1.5 $-2.5 \mathrm{~mm}$ horizontally. ${ }^{9}$
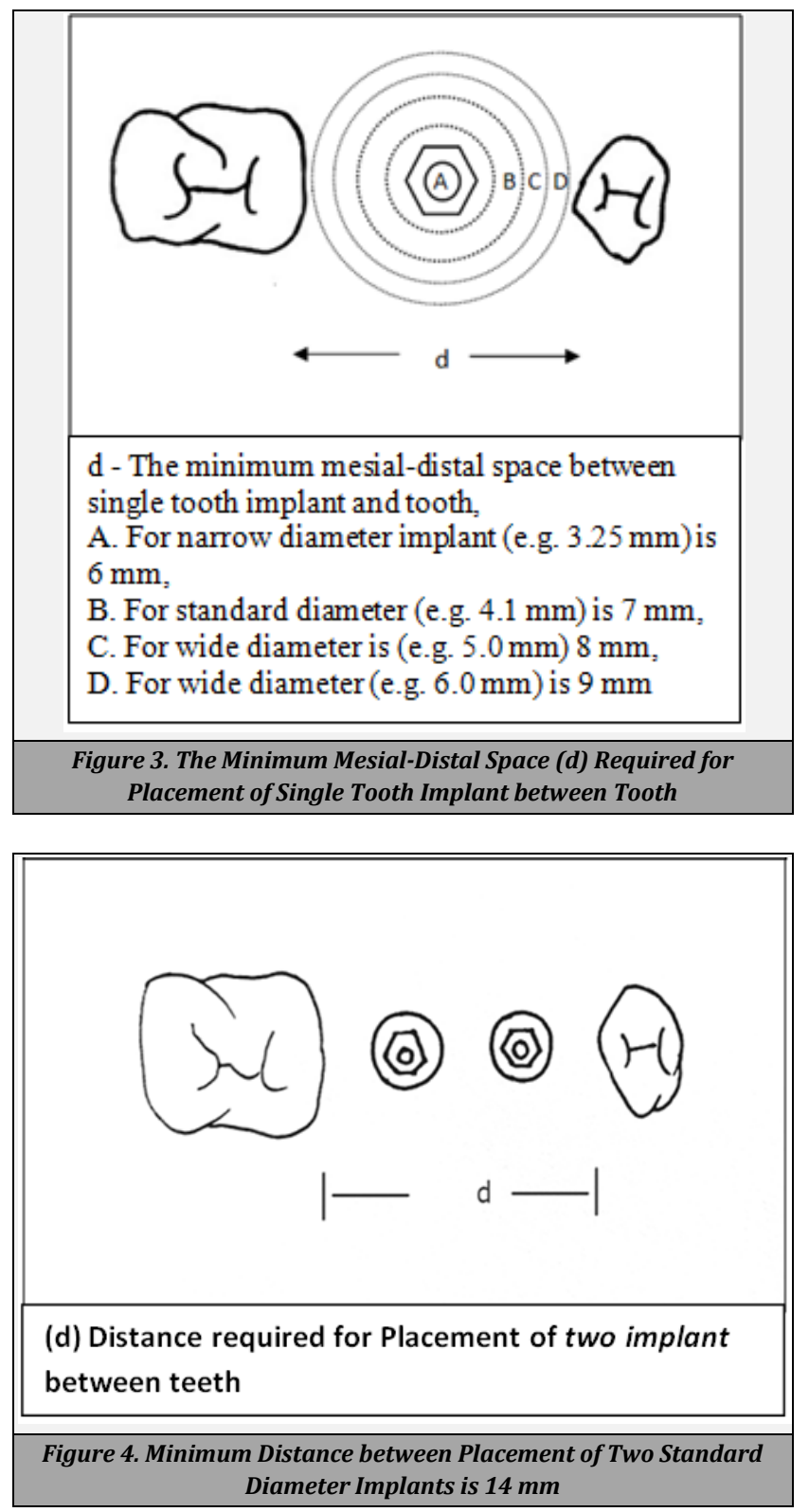

\section{Gingival Phenotype}

Studies have shown that the periodontal phenotype (thick or thin gingiva) affects the dimension of the periodontal tissue around implant.16-18 A thick phenotype $(>2.5 \mathrm{~mm})$ is described as resilient and can therefore cause formation of pocket, while a thin phenotype $(<2.5 \mathrm{~mm})$ is friable and thus often susceptible to gingival recession following mechanical trauma and/or surgical manipulation. ${ }^{16-19}$ Thus, gingival phenotype becomes an important aspect of peri-implant aesthetics. Two phenotypes have been suggested: Thin scalloped and flat thick.6,20,21 To evaluate the phenotype, simplest method is by using periodontal probes. The probe can be inserted in the facial aspect of the peri-implant sulcus. The 
phenotype is said to be thin, if the outline of the underlying probe is visible through peri-implant mucosa and thick if the probe cannot be seen through the mucosa. ${ }^{22}$ Thin phenotype exhibit a deficient underlying osseous support and poor vascularization, and thus poor surgical outcomes leading to increased gingival recessions and loss of the interproximal tissue. Conversely, thick underlying osseous support is observed under thick tissue along with good vascular supply which provides resistant to physical injuries and also inhibits bacterial access. Thin phenotype could cause the bone loss of $1.45 \mathrm{~mm}$ with first year of function. Thus, augmentation of thin mucosa should be taken into account before implant placement.

\section{Interdental Papillary Aesthetics}

Lower the interproximal contact area to the bone crest distance, higher will be the inter-papillary tissue volume. At a distance of $<5 \mathrm{~mm}$, complete papillae fill was observed $100 \%$ of the time; $5-7 \mathrm{~mm}$ of this distance shows $56 \%$ of papilla fill rate. If the distance exceeds $7 \mathrm{~mm}$, the space fill is only $27 \%$ of the time. ${ }^{9}$ Implants must be placed in the so-called 'safe zone' for best aesthetic results.

The apico-coronal position of the implant should be 2 - 3 $\mathrm{mm}$ apical to cemento-enamel junction (CEJ) of adjacent teeth. After achieving the optimal implant position, the transitional tissue could be altered using an abutment to create a profile that replicates the natural teeth and prove soft tissue support.

At the time of uncovering the implant, this step can be performed which can be transferred to final restoration later. Patient's natural teeth act as a guide to maintain the volume of papilla and support. 6

Position of Tooth, Amount of Keratinized Tissue and Type of Gingival Scallop

Thin interdental bone due to its root proximity becomes more vulnerable to the resorptive process, which further influence the soft tissue responsible for soft tissue loss. While in case of teeth with thick interproximal bone, comparatively show less bone as well as soft tissue loss. Morphologically, gingival scallop can be high, normal or flat. ${ }^{23}$ The gingival architecture also has an impact on peri implant tissue health and aesthetics. In flat gingival contour, the coronal level of interproximal tissue is low than facially. The manipulation of the soft tissue surrounding the implant in a desired way can serve durable success. For this, the presence of adequate amount of keratinized mucosa is essential. A broad mucosal band i.e. more than $2 \mathrm{~mm}$ is linked to reduced mucosal recession and attachment loss compared to narrow band of less than $2 \mathrm{~mm}$ 19

\section{Smile Line}

The ultimate aesthetics at smile depends on the interplay among the three components of aesthetic zone: that is the teeth, the lips and the gingiva. Lip line is an important factor as it determines the extent of display of implant prosthesis and the peri implant mucosa. Depending upon this, it is categorized whether a particular smile has high, medium, or a low lip line. A high smile line poses considerable challenges when planning for implant supported restorations because the restoration and peri-implant tissues are completely displayed, in such cases surgical procedures can help to reposition the lip at aesthetic level.

\section{Hard Tissue Factors}

The Platform Switch Concept

Degidi et al. (2008) demonstrated that whenever there is an alteration in horizontal relation of outer edge of implant and smaller diameter component (platform switching), a reduction in crestal bone loss is observed. Conventional type of implant utilizes the abutments which frequently fuse with the implant shoulder in the contact zone $\left(\approx 180^{\circ}\right)$ while in platform switching, the outer edge of implant makes an angle of $90^{\circ}$ with outer edge of abutment (Figure 5). Contact point at the junction of implant and abutment shows the presence of micro gap demonstrating "bacterial contamination," which has negative impact on the peri-implant crestal bone health and ultimately leading to bone loss. Resultant crestal bone loss may show vertical and horizontal pattern. This whole process is actually an effect of the interaction of bacteria at the implant abutment junction (IAJ) whenever it is exposed to the oral environment. The concept of platform switching basically shifts the inflammatory zone away from the crestal bone by placing the micro gap at a distant location from the implant shoulder and near to the axis of an implant. The findings have been proven with long term radiographic follow up, showed smaller changes than estimated vertical dimension in the crestal bone height around these implants than classically observed vertical bone height around implants restored traditionally with prosthetic components of same diameter. ${ }^{5,25}$

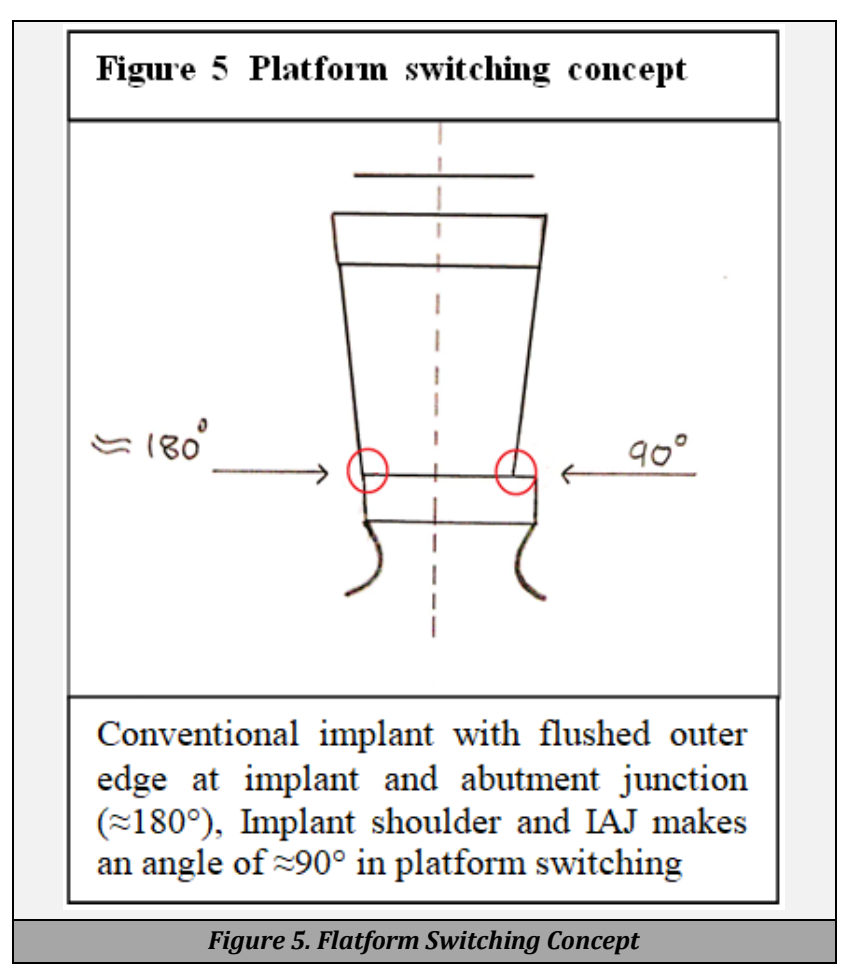

Collar Geometry and Micro Gap Size of Implant Implant collar refers to the neck of implant which plays an important role to improve the integrity of the soft tissue of the implant. This includes the surface of implant neck which can be microtextured or macro-textured. The objective of this design is to reinforce the balance of interface for both soft and hard tissue and prevent the marginal bone alteration which is seen usually in the first year of placement of implant. The anticipated levels of crestal bone loss as demonstrated in an in-vivo study of the laser microtextured implant surface by Pecora et al. (2009) showed that the laser locked surface 
treatment provides reduction in of the crestal bone loss to 0.59 $\mathrm{mm}$ after the period of 3 years. ${ }^{26,5}$ The implant design and surface modification act as an attributing factor for reduction of the crestal bone stress through mixture of size of the micro gap between the implant and therefore the abutment has slight influence on marginal bone remodelling27,5 Subjects having implants with rough wide-neck design demonstrated lower probing depth and minor marginal bone loss compared to individuals receiving implants with rough reduced-neck implants. ${ }^{28}$ Systematic review on Evaluation of Implant Collar Surfaces for Marginal Bone Loss by Koodaryan R (2016) showed that machined neck implants show more bone loss than insertion of implants with rough surfaced micro threaded neck. ${ }^{29}$

The implant abutment interface (IAI) micro gap, defined as the microscopic space between implant and corresponding abutment exists. ${ }^{30}$ Better results are seen with the smaller micro gap between the titanium abutment and titanium implant than other materials. Regarding the manufacturing technique, the pre-machined abutments exhibit smaller micro gaps than those of cast on and castable abutments. IAI connection style, Morse taper connection is sealed better than butt joint connection. ${ }^{31}$

\section{Size of Implant}

Size of implant plays an important role. It varies with amount of space available and according to the location of implant placement in mouth. In 1990, larger diameter implants were manufactured with diameter greater than 4 - $10 \mathrm{~mm}$ diameter. In order to simulate the diameter of tooth being replaced, the large diameter implants were manufactured which aid in improvement of appearance of the implant crown and thus provide better esthetics. ${ }^{32} \mathrm{~A}$ study done by Luigi et al. (2020) found that rough reduced neck showed increased marginal bone loss and probing depth when compared to rough wide necked implants. 33

\section{Abutment Disconnection and Microlesion}

During implant placement, the healing or temporary abutment are attached and detached many times between implant placements, final restoration delivery which can cause soft tissue disruption and apical migration of the epithelial tissue surrounding implant neck resulting in bone resorption. Every time the abutment is disconnected and reconnected, this type of resorption occurs. The bone resorption around the implant is anticipated once the second - stage surgery is done. To avoid this clinical picture, one-stage protocol, that is immediately placing the implant without further removing it on the day of final abutment insertion or at second-stage surgery in cases of submerged implants (two-stage protocol) was suggested. ${ }^{20}$ The implant abutment junction impedes apical propagation of epithelium with a great connective tissue attachment. This is disrupted by plaque which might replicate the hazard on the crestal alveolar bone. ${ }^{34}$

\section{CONCLUSIONS}

In current era, the requirement for cosmetic appearance requires further emphasis on periodontal aesthetics and rehabilitation in aesthetic zone is complex and demanding.
Implant success mandates gingival aesthetics, restoration of function, osteo-integration of endosseous implant and patient satisfaction. Information about implant aesthetics can help dentists to institute soft tissue as well as hard tissue changes in the oral cavity so as to fulfil the aesthetic need of the individual. To avoid prospective post-treatment complexities, pre-consultation with an analysis of aesthetic risk assessment at chair side can improve the success of implants. ${ }^{34}$

Financial or other competing interests: None.

Disclosure forms provided by the authors are available with the full text of this article at jemds.com.

\section{REFERENCES}

[1] Pallacci P. Peri - implant soft tissue management: Papilla regeneration technique. In: Palacci $\mathrm{P}$, Ericcsson I, Engstrand $\mathrm{P}$, et al, eds. Optimal implant positioning and soft tissue management for the branemark system. Chicago: Quintessence 1995:59-70.

[2] Jepsen S, Caton JG, Albandar JM, et al. Periodontal manifestations of systemic diseases and developmental and acquired conditions: consensus report of workgroup 3 of the 2017 World Workshop on the Classification of Periodontal and Peri-Implant Diseases and Conditions. J Clin Periodont 2018;45 Suppl 20:S219-29.

[3] Berglundh T, Lindhe J, Ericsson I, et al. The soft tissue barrier at implants and teeth. Clin Oral Implants Res. 1991;2(2):81-90.

[4] Berglundh T, Lindhe J, Jonsson K, et al. The topography of the vascular systems in the periodontal and peri -implant tissues in the dog. J Clin Periodontol 1994;21(3):189-93.

[5] Dhir S. The peri-implant esthetics: an unforgettable entity. J Indian Soc Periodontol 2011;15(2):98-103.

[6] Berglundh T, Lindhe J. Dimension of the periimplant mucosa. Biological width revisited. J Clin Periodontol 1996;23(10):971-3.

[7] Batra R, Kalra S, Batra H. Implant esthetics. Indian J Dent 2012;1;3(1):15-20.

[8] Levin EI. Dental esthetics and the golden proportion. J Prosthet Dent. 1978;40(3):244-52.

[9] Tarnow DP, Cho SC, Wallace SS. The effect of inter-implant distance on the height of inter-implant bone crest. J Periodontol 2000;71(4):546-9.

[10] Esfahrood ZR, Kadkhodazadeh M, Gholamin P, et al. Biologic width around dental implants: An updated review. J Dent Mater and Tech 2016;5(2):68-81.

[11] Tarnow DP, Magner AW, Fletcher P. The effect of the distance from the contact point to the crest of bone on the presence or absence of the interproximal dental papilla. J Periodontol 1992;63(12):995-6.

[12] Atieh MA, Ibrahim HM, Atieh AH. Platform switching for marginal bone preservation around dental implants: a systematic review and meta-analysis. J Periodontol 2010;81(10):1350-66.

[13] Newman MG, Takei H, Klokkevold PR, et al. Newman and Carranza's Clinical Periodontology. 10th edn. Elsevier Health Sciences 2006.

[14] Scott H. Implant placement in the esthetic zone. Decisions in Dentistry 2018;4(3):22-4. 
[15] Olsson M, Lindhe J. Periodontal characteristics in individuals with varying form of the upper central incisors. J Clin Periodontol 1991;18(1):78-82.

[16] Kois J. Predictable single tooth peri-implant esthetics: five diagnostic keys. Compend Contin Educ Dent 2001;22(3):199-206.

[17] Müller HP, Heinecke A, Schaller N, et al. Masticatory mucosa in subjects with different periodontal phenotypes. J Clin Periodontol 2000;27(9):621-6.

[18] Sanavi F, Weisgold AS, Rose LF. Biologic width and its relation to periodontal biotypes. J Esthet Dent 1998;10(3):157-63.

[19] George JP, Dhir S. Soft tissue and esthetic considerations around implants. J Int Clin Dent Res Organ 2015;7(3):11931.

[20] Abrahamsson I, Berglundh T, Lindhe J. The mucosal barrier following abutment dis / reconnection. J Clin Periodontol 1997;24(8):568-72.

[21] Hermann JS, Buser D, Schenk RK, et al. Biologic Width around one - and two - piece titanium implants. Clin Oral Implants Res 2001;12(6):559-71.

[22] Kan JYK, Rungcharassaeng K, Umezu K, et al. Dimensions of peri-implant mucosa: an evaluation of maxillary anteriorsingle implants in humans. J Periodontol 2003;74(4):557-62.

[23] Kois JC. Altering gingival levels: the restorative connection part i: biologic variables. J Esthet Restor Dent 1994;6(1):3-7.

[24] Degidi M, Iezzi G, Scarano A, et al. Immediately loaded titanium implant with a tissue-stabilizing / maintaining design ('beyond platform switch') retrieved from man after 4 weeks: a histological and histomorphometrical evaluation. A case report. Clin Oral Implants Res 2008;19(3):276-82.
[25] Persson LG, Lekholm U, Leonhardt $\AA$, et al. Bacterial colonization on internal surfaces of Brånemark system $\AA$ implant components. Clin Oral Implants Res 1996;7(2):90-5.

[26] Pecora GE, Ceccarelli R, Bonelli M, et al. Clinical Evaluation of Laser Microtexturing for Soft Tissue and Bone Attachment to Dental Implants. Implant Dent 2009;18(1):55-66.

[27] Hermann JS, Schoolfield JD, Schenk RK, et al. Influence of the size of the microgap on crestal bone changes around titanium implants. a histometric evaluation of unloaded non-submerged implants in the canine mandible. J Periodontol 2001;72(10):1372-83.

[28] Montemezzi P, Ferrini F, Pantaleo G, et al. Dental implants with different neck design: a prospective clinical comparative study with 2-year follow-up. Materials 2020;13(5):1029.

[29] Koodaryan R, Hafezeqoran A. Evaluation of implant collar surfaces for marginal bone loss: a systematic review and meta - analysis. Biomed Res Int 2016;2016:4987526.

[30] Scarano A, Mortellaro C, Mavriqi L, et al. Evaluation of microgap with three-dimensional $\mathrm{x}$-ray microtomography: internal hexagon versus cone morse. J Craniofac Surg 2016;27(3):682-5.

[31] Liu Y, Wang J. Influences of microgap and micromotion of implant-abutment interface on marginal bone loss around implant neck. Arch Oral Biol 2017;83:153-60.

[32] Misch CE. Contemporary implant dentistry. Implant Dent 1999;8(1):90.

[33] Canullo L, Tallarico M, Gracis S, et al. Clinical considerations on strategies that avoid multiple connections and disconnections of implant abutments. Int J Periodont Rest Dent 2020;40(1):9-17.

[34] Levine R, William M. Esthetic risk assessment in implant dentistry. Inside Dent 2012;8(8):66-71. 